\title{
OPORTUNIDADES PARA MELHORAR O DESEMPENHO TÉRMICO EM TORRES DE RESFRIAMENTO
}

\author{
S. ÁVILA FILHO ${ }^{1}$, B. S. NÓBREGA ${ }^{1}$ \\ ${ }^{1}$ Universidade Federal da Bahia, Escola Politécnica \\ E-mail para contato: bruna_sbf@hotmail.com
}

\begin{abstract}
RESUMO - Hoje o que mais se ouve falar é sobre sustentabilidade e a real e crescente escassez de água que vem assolando o Brasil. As indústrias estão se conscientizando e buscando meios sustentáveis e vias alternativas para diminuírem seus custos, economizarem energia, serem sustentáveis, mas sem alterar seu processo de produção. Mas o que muitas indústrias não notam é que existe uma integração entre os processos e equipamentos que não estão diretamente ligados com o processo de produção em si, afetam significativamente o consumo de água e energia da indústria, insumos esses que estão cada vez mais caros e escassos. Um desses equipamentos são as torres de resfriamento, equipamento que tem como objetivo resfriar a água através do seu contato com o ar atmosférico, água essa utilizada em outros processos onde se faz necessário a retirada de calor. Esta água após o resfriamento retorna para o processo em um novo ciclo sendo reutilizada. As torres estão situadas na área de utilidades da indústria, é um dos equipamentos que mais consome água e energia na indústria e influencia nas condições operacionais do processo. Este estudo tem por objetivo mostrar a importância desse sistema de resfriamento onde através de auditorias e testes de desempenho pode-se diminuir o consumo de água e energia da indústria e evitar o seu desperdício além de melhorar as condições do processo como um todo.
\end{abstract}

\section{INTRODUÇÃO}

Torres de resfriamento são equipamentos que tem como objetivo resfriar a água através do seu contato com o ar atmosférico, água essa utilizada em outros processos onde se faz necessário a retirada de calor. Esse processo se dá pela transferência de calor e massa entre o ar e a água que ocorre devido ao gradiente de temperatura e o de concentração. Calor sensível é trocado devido a diferença de temperatura entre a água e o ar onde o ar tem sua temperatura aumentada, e também há a transferência de massa entre eles que é o calor latente, e devido ao gradiente de concentração parte da água é evaporada e transferida para o ar, aumentando assim a sua umidade. A transferência de massa ocorre pelo fato das duas fases estarem buscando o equilíbrio. Considera-se que $80 \%$ desse resfriamento da água é devido à transferência de calor latente e $20 \%$ é devido ao calor sensível. (CHEREMISINOFF; CHEREMISINOFF, 1981).

\subsection{Estudo da Psicrometria}


Para o estudo e entendimento de torres de resfriamento, se faz necessário um conhecimento básico de psicrometria, que é o estudo de processos que envolvam o ar úmido utilizando as propriedades termodinâmicas. Pela carta psicrométrica podemos estudar o sistema ar-água e determinar suas propriedades. Um conceito importante dentro da psicrometria é a temperatura de bulbo úmido que é a temperatura atingida pela água quando uma pequena quantidade dessa água é evaporada em uma corrente de ar úmido não saturado, e é esse o processo que ocorre nas torres de resfriamento. A temperatura de bulbo úmido é, na teoria, a menor temperatura a qual se consegue resfriar a água em uma torre. Na prática, essa temperatura não é alcançável, pois para que isso ocorresse seria necessário que toda a água entrasse em contato com o ar e que essas duas correntes ficassem em contato pelo maior período de tempo possível, o que não ocorre.

\subsection{Teoria de Merkel}

A teoria hoje mais aceita que explica a transferência de calor e massa entre o ar e a água é a Teoria de Merkel, onde os dois processos são combinados em um global que tem no potencial de entalpia sua força motriz de resfriamento. Para entender essa teoria consideramos uma gota de água suspensa no ar exemplificado na figura 1.

Figura 1- Gotícula de água

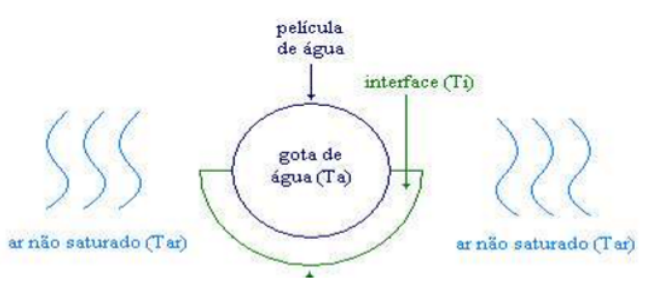

Essa gota está envolta por uma película de ar saturado que possui a mesma temperatura que a água e é justamente a interface ar-água. Nessa interface considera-se que não há resistência ao transporte de calor e massa e que as duas fases estão em equilíbrio. Para os cálculos da transferência de calor e massa é considerada essa interface entre as duas fases e pode ser obtido através da equação 1 .

$$
d Q=K \cdot d S \cdot\left(h_{u}-h_{a}\right)
$$

Esses estudos tanto da transferência de calor e massa, como da psicrometria, são parâmetros importantes utilizados para se modelar uma torre de resfriamento. Além desses parâmetros, se faz necessário o balanço de massa e energia da torre, o cálculo da altura da torre, da curva de saturação do ar, da curva de operação da torre e determinar a temperatura de saída da água da torre. Com essas e outras informações adicionais se faz possível a modelagem de uma torre. 


\section{METODOLOGIA}

A Torre de resfriamento é o sistema de resfriamento mais utilizado pelas indústrias nos dias de hoje principalmente para vazões elevadas e restrições na condição de processo dos usuários da água de resfriamento da torre. Ela está associada a fatores econômicos e ecológicos pois ela resfria a água para ser reutilizada e assim economizará no consumo de água da indústria e não irá descartar uma água quente que poderia prejudicar a fauna e flora do ambiente em que ela seria descartada. Apesar dessa "economia de água", a torre é um dos equipamentos que mais se consome água e energia na indústria pois se faz necessário uma reposição de água para suprir perdas devido a purga, arraste e evaporação, e se a torre estiver em má funcionamento, que é o que geralmente ocorre, essa reposição será muito maior se não dada a devida atenção a este equipamento. Além disso, a torre influencia nas condições operacionais do processo como um todo pois por essas torres são dissipadas grandes cargas de energia térmica de processos que precisam dessa dissipação de energia para manter seus parâmetros e sua produção, e também a temperatura dessa água de resfriamento influencia nas pressões dos condensadores de topo da coluna de destilação.

Apesar das indústrias saberem de toda essa importância que a torre tem para o processo, o que acontece é que esse equipamento é avaliado somente durante a parte de projeto e especificação da planta e por ser uma parte integrante da área de utilidades da planta e estar topograficamente afastada das unidades produtivas da fábrica, é um equipamento bastante negligenciado pelas indústrias. Hoje em dia os cenários mais comumente encontrados nas indústrias são de torres em más condições e funcionamento. Devido a importância desse equipamento para o processo, a torre e o circuito que a água de resfriamento percorre devem receber uma atenção especial na análise sistêmica de um processo industrial, e muitas vezes, a solução de alguns problemas operacionais podem ser encontrados ampliando-se o foco do estudo para as utilidades da indústria. Mas como realizar esse estudo nas torres de resfriamento? Através de auditorias e testes de desempenho.

\subsection{Auditorias}

O objetivo de uma auditoria é verificar o estado e as condições de operação da torre para assim encontrar oportunidades de melhoria do desempenho térmico dessas torres. A metodologia encontrada para melhor avaliação do desempenho das torres segue as seguintes etapas:

1. Análise de dados de processo e tratamento de água: consiste em verificar o seu desempenho através de cálculos de balanço de massa e energia para a verificação de erros de equações ou desfalques perante a operação e o projeto.

2. Verificação dos usuários da água de resfriamento: consiste em observar todos os equipamentos do sistema de resfriamento por onde a água de resfriamento circula para verificar se há presença de incrustações, corrosão e algas, que são os principais problemas em sistemas de água de resfriamento. A corrosão é associada a tendência natural dos metais de retornarem ao seu estado mais estável, ou seja, de seus óxidos e sais. A incrustação está associada cristalização e a deposição de sais pouco solúveis. A formação de algas está associada a proliferação de microrganismos em condições favoráveis para essa proliferação 
ocorrer. A presença desses fatores causam inúmeras perdas no processo como queda na eficiência e vazamento dos trocadores de calor, entupimento das tubulações, redução da resistência mecânica dos materiais, entre outros.

3. Visitação em campo para checagem dos pontos críticos que influenciam o desempenho da torre: corresponde à auditoria em si e consiste em aplicar um check-list para verificar pontos relevantes para a manutenção e operação da torre. Nesse check-list constam inúmeras verificações, como por exemplo, aparência da água na bacia fria, aparência física do recheio quanto a estado de manutenção, aparência visual quanto a presença de algas no recheio e bacia quente, fuga de ar pela parte lateral da torre, amperagem e vibração dos ventiladores, vazamento de água, entre outros.

Essas são as etapas tanto da parte teórica como da prática da realização de uma auditoria em uma torre de resfriamento. Através de análises de vários relatórios de auditoria realizados pelo Professor Ávila em indústrias como a Caraíba Metais, pode-se notar que o estado geral das torres de resfriamento nas indústrias hoje em dia é decadente. Nos relatos e imagens presentes nos relatórios do Professor Ávila vê-se formação de algas no recheio da torre e nas venezianas, venezianas quebradas e danificadas, incrustações nas aletas e deposição de sais nas tubulações, vazamentos na bacia de água fria, transbordamento da bacia de água quente, entre outros.Com base nos resultados obtidos em todas as etapas, se faz necessário a criação de um plano de manutenção, controle e operação para a melhor otimização dos recursos hídricos e energéticos da planta industrial.

\subsection{Testes de Desempenho}

O segundo estudo a ser realizado nas torres é o teste de desempenho, que consiste em verificar qual seria o desempenho da torre caso ela estivesse operando nas condições de projeto. Esse teste é realizado segundo as recomendações do CTI (Cooling Tower Institute) que indica dois métodos que podem ser utilizados: o método das curvas de demanda e característica e o método da curva de desempenho. Foi utilizado o método das curvas de demanda e característica para torres de contra corrente, encontrado no Curso de Torres do Professor Eny Cassetta, para exemplificar o teste de desempenho.

Toda torre possui sua curva de demanda e característica de projeto. A curva de demanda é obtida através da integração da equação de Merkel que representa a capacidade efetiva requerida da torre e é representada pela equação 2.

$$
\left.\frac{K \cdot a \cdot V}{L}=\frac{t_{U Q}-t_{U F}}{4} \cdot C_{L} \cdot\left[\left(\frac{1}{h_{U 1}-h_{A 1}}\right)+\left(\frac{1}{h_{U 2}-h_{A 2}}\right)+\right]\left(\frac{1}{h_{U 3}-h_{A 3}}\right)+\left(\frac{1}{h_{U 4}-h_{A 4}}\right)\right]
$$

Já a curva característica é obtida através da equação 3 e representa a capacidade efetiva de transferência de uma torre.

$$
\frac{K \cdot a \cdot V}{L}=C \cdot\left(\frac{L}{G}\right)^{-n}
$$


Essas curvas são encontradas variando-se os valores da razão L/G, e aplicando-se nas equações acima citadas. Com isso, encontra-se o termo K.a.V/L correspondente a cada valor de L/G. Esses valores são plotados em um gráfico gerando as curvas de demanda e característica do projeto onde o ponto de encontro dessas curvas é o ponto de operação de sua torre nas condições de operação( vazões e temperaturas do projeto).

De posse desses dados, é realizado um teste na torre onde o $\mathrm{L} / \mathrm{G}$ do teste é calculado através da equação 4.

$$
\left(\frac{L_{T}}{G_{T}}\right)_{\text {teste }}=\frac{L_{T(\text { teste })}}{L_{T(\text { projeto })}} \cdot\left(\frac{P_{(\text {projeto })}}{P_{(\text {teste })}}\right)^{1 / 3} \cdot\left(\frac{P_{\text {ar }(\text { teste })}}{P_{\text {ar }(\text { projeto })}}\right)^{1 / 3} \cdot\left(\frac{V_{\text {ar }(\text { teste })}}{V_{\text {ar }(\text { projeto })}}\right) \cdot\left(\frac{L_{T}}{G_{T}}\right)_{\text {projeto }}
$$

Antes, se faz necessário determinar a temperatura do ar quente que é determinado através de um procedimento onde primeiro estimou um valor para essa temperatura, que pode ser a média entre os valores das temperaturas de água quente e fria, depois determinamos o volume específico e massa específica do ar no teste. Jogamos esses valores na fórmula e calculamos o $\mathrm{L}_{\mathrm{T}} / \mathrm{G}_{\mathrm{T}}$ do teste. Com esse $\mathrm{L}_{\mathrm{T}} / \mathrm{G}_{\mathrm{T}}$ calculamos a entalpia da água quente pela equação 5 .

$$
h_{U Q}=h_{W B}+C_{L} \cdot \frac{L_{T}}{G_{T}} \cdot\left(t_{U Q}-t_{U F}\right)
$$

De posse dessa entalpia, determinamos a nova temperatura da água quente usando tabelas ou cartas psicrométricas. Ao comparar esse novo valor de temperatura encontrado com a estimativa anterior, se a diferença for maior que $0,1{ }^{\circ} \mathrm{F}$ deve-se repetir $\mathrm{o}$ procedimento novamente, se for menor que $0,1^{\circ} \mathrm{F}$, podemos considerar válido o valor encontrado de $\mathrm{L}_{\mathrm{T}} / \mathrm{G}_{\mathrm{T}}$ do teste. Após encontrar esse valor, calculamos o ponto correspondente ao k.a.V/L da curva característica efetiva da torre pela equação integrada de Merkel Encontrando esse ponto no gráfico, traçamos uma curva, ou reta, paralela à de projeto como exmplificado na figura 2. O ponto de encontro dessa nova curva característica com a curva de demanda do projeto é o seu ponto de operação corresponde ao $\mathrm{L} / \mathrm{G}$ com o qual a torre funcionaria caso as temperaturas de bulbo úmido, água quente $\mathrm{e}$ água fria fossem as de projeto. A relação entre esse $\mathrm{L} / \mathrm{G}$ e o de projeto é a eficiência de sua torre.

Figura 2- Curva de demanda e característica

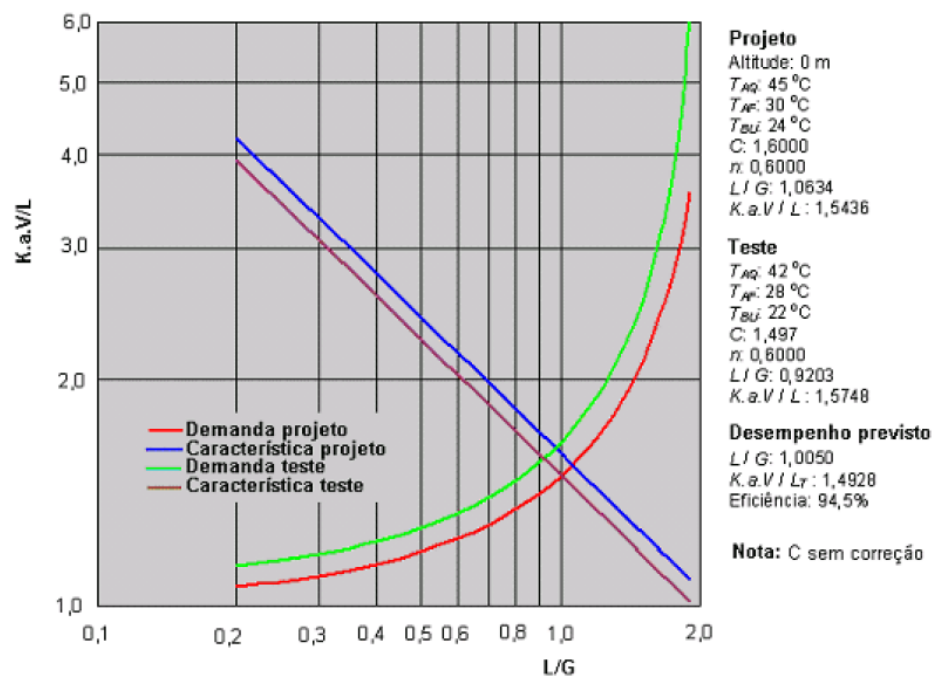




\section{CONCLUSÃO}

A escassez de água no Brasil se tornou uma realidade nos dias atuais como pode já ser visto de forma rigorosa em estados como São Paulo e Rio de Janeiro, resultado esse causado por inúmeros fatores como efeito estufa e poluição. A indústria é um dos grandes responsáveis por esse alto consumo de água pois $17 \%$ da água é consumida pelo setor industrial e por isso tem grande responsabilidade em reduzir esse consumo. As torres de resfriamento consomem aproximadamente $50 \%$ da água utilizada pela indústria logo, um melhor desempenho delas acarretaria num maior reaproveitamento dessa água consumida. De acordo com estudos realizados pelo Professor Ávila, se reduzir a temperatura da água de resfriamento em $1^{\circ} \mathrm{C}$ economiza-se cerca de $184 \mathrm{GJ} / \mathrm{h}$, o que equivale a uma economia de combustível de R\$ 50 milhões por ano.

O potencial de economia de água e energia das torres de resfriamento é alto e se investido tempo e dinheiro nestes equipamentos, o resultado favorecerá tanto a indústria como a sociedade. A indústria necessita urgentemente se conscientizar de que é preciso economizar ou chegará o tempo em que não existirão mais recursos para que a indústria continue operando.

\section{NOMENCLATURA}

Q - calor transferido, $\mathrm{J} / \mathrm{s}$;

$\mathrm{K}$ - coeficiente global de transferência de massa, $\mathrm{kg} /(\mathrm{m} 2 . \mathrm{s})$;

$\mathrm{S}$ - superfície total de transferência de calor, m2 ;

hU - entalpia da película de ar na temperatura da água, J/Kg de ar seco;

hA - entalpia do ar não saturado, j/kg de ar seco;

hA1 ,hA2 , hA3 e hA4 - entalpia do ar saturado;

$\mathrm{tU} 1, \mathrm{tU} 2, \mathrm{tU} 3$ e tU4 - temperaturas;

a - área de interface por unidade de volume de enchimento, $\mathrm{m} 2 / \mathrm{m} 3$;

V- volume específico de enchimento por unidade de área transversal, m2/m3;

L - vazão mássica da água, $\mathrm{kg} /(\mathrm{s} . \mathrm{m} 2)$;

G- vazão mássica de ar, kg/(s.m2) ;

CL - capacidade calorífica da água, J/(kg.K) ;

tUQ - temperatura da água quente,na entrada da torre, $\mathrm{K}$; 
tUF - temperatura da água fria, na saída da torre, $\mathrm{K}$;

hBU - entalpia do ar na temperatura de bulbo úmido, $\mathrm{J} / \mathrm{kg}$ de ar seco;

$\mathrm{P}$ - potência dos motores dos ventiladores, $\mathrm{kW}$;

$\rho$ - massa específica do ar, $\mathrm{kg} / \mathrm{m} 3$;

$v$ - volume específico do ar úmido, $\mathrm{m} 3 / \mathrm{kg}$ de ar seco.

\section{REFERENCIAS}

Ávila, S.F. Boas Práticas em torres de resfriamento: comparação entre auditorias industriais.

Ávila, S.F. Auditoria de Torres de resfriamento Caraíba Metais.

Casseta, E. Curso Teórico de Torres de Resfriamento. 